\title{
Acordo de quotistas: breves considerações sobre 'importação' do instrumento pelas sociedades limitadas
}

\author{
Quotaholders' agreement: brief considerations \\ over importation of the corporate instrument \\ by the limited liability companies
}

\author{
Irena Carneiro Martins
}

Mestre em Direito Privado pela Universidade Federal da Bahia (UFBA), professora de Direito Empresarial na Universidade Salvador (UNIFACS), Salvador, BA - Brasil, e-mail: irenamartins@gmail.com

\section{Resumo}

Este artigo busca apresentar algumas considerações acerca da utilização do instrumento parassocial, conhecido como acordo de acionistas (típico, portanto, das sociedades anônimas), no ambiente das sociedades limitadas. Ao passo em que as sociedades anônimas contam com diploma legal que regula e delimita o alcance do acordo de acionistas, nas sociedades limitadas é preciso considerar as normas gerais de Direito Societário, as regras específicas das limitadas, bem como os limites da supletividade da Lei das S.A., quando aplicável. É objetivo do presente artigo sugerir parâmetros para a 
celebração do acordo de quotistas no ambiente das sociedades limitadas, delinear seus alcances e limitações.

Palavras-chave: Direito Societário. Acordo de quotistas. Sociedades limitadas.

\section{Abstract}

This essay aims to present some considerations concerning the use of paracorporate covenant known as shareholders' agreement (typical in corporations) in the environment of the limited liability companies. If, by one side, corporations rely on statute that rule and limit the purview of the shareholders agreement, on the other side, such paracorporate agreement regarding limited liability companies must consider the general corporate law rules, the specific rules applicable to limited liability companies and the limits of the corporate act's supplementation, if applicable. It is a purpose of this essay to suggest parameters for the execution of the quotaholders agreement, as well as to delineate its purviews and limitations.

Keywords: Corporate Law. Quotaholders' agreement. Limited liability companies.

\section{Introdução}

$\mathrm{O}$ acordo de acionistas, contrato parassocial subordinado ao estatuto social das companhias e à Lei n. 6.404/76, a Lei das Sociedades por Ações, daqui por diante referida como LSA (LAMY FILHO, 2007, p. 299), trata-se de instrumento bastante utilizado entre os acionistas de sociedades por ações e acaba por cumprir uma função de norma secundária das referidas sociedades, para lembrar expressão cunhada por Fabio Konder Comparato: "o acordo de acionistas é 'norma secundária' em confronto com o estatuto e, a fortiori, a lei, os quais assumem o papel de 'norma primária' no sentido hierárquico" (COMPARATO, 1981, p. 75).

O acordo de acionistas vem regulado na LSA em seu artigo 118 ao longo de seus 11 parágrafos. E pode-se dizer que, ao longo do dispositivo, a LSA prescreve, dentre outros aspectos, o que se segue: 
a) a abrangência do acordo, na medida em que determina, no caput, que o acordo trata de compra e venda de ações, preferência na aquisição, exercício do direito a voto ou poder de controle;

b) a condição de observância pela companhia, qual seja, o arquivamento do acordo na sua sede;

c) o requisito para oposição erga omnes, qual seja, averbação nos livros de registro e, se aplicável, nos certificados das ações;

d) a proteção conferida para garantir os termos do acordo, na medida em que o referido instrumento, além de admitir execução específica das obrigações nele assumidas, garante que os votos em assembleia dados em desacordo com o acordo de acionistas não serão computados pelo presidente da assembleia ou do órgão colegiado de deliberação, desde que devidamente arquivados na sede da companhia;

e) os limites do acordo de acionistas, uma vez que: i) tal instrumento jamais poderá ser invocado para eximir o acionista de responsabilidade no exercício do direito de voto ou do poder de controle; ii) as ações vinculadas a acordo não poderão ser negociadas em bolsa ou no mercado de balcão.

Esse instrumento, repita-se, de caráter parassocial, de extrema importância para acionistas de sociedades anônimas, principalmente aquelas que têm seu capital votante mais dividido, pulverizado, vem se revelando - ultimamente - de grande valia para os sócios das sociedades limitadas.

Atribui-se essa crescente atenção que o acordo de quotistas vem recebendo, por parte daqueles que participam de capital social de sociedade limitada, ao fato de que, desde o início da vigência do Código Civil de 2002, somente se pode falar em controle efetivo nessas sociedades se estivermos diante de uma participação societária equivalente a 3/4 ou $75 \%$ do capital social. Daí falar-se, atualmente - no âmbito das limitadas -, nessa modalidade de acordo que, nesse caso, chama-se acordo de quotistas. 


\section{O acordo de quotistas e suas limitações}

Os acordos de acionistas, que exercem "papel vivificador do direito acionário" (COMPARATO; SALOMÃO FILHO, 2008, p. 217), na medida em que - externando a autonomia da vontade das partes, no caso, os acionistas - podem suprir lacunas da lei e do próprio estatuto, desde que respeitados os limites impostos tanto pela primeira quanto pelo segundo, acabam por assumir, no âmbito das limitadas, uma função balizadora e até mesmo de "espelho", uma vez que o Código é omisso no tratamento do acordo.

Assim sendo, os quotistas - tal como os acionistas de uma S.A. buscam regular o poder de controle societário e o que se chama 'voto em bloco', bem como a alienação de quotas e direito de preferência na aquisição destas.

Como referido na introdução, é de se especular que a atenção que esteja sendo dada a tais contratos parassociais se deva muito mais às questões de exercício de poder de controle societário do que aos demais aspectos usualmente abrangidos pelos acordos de acionistas, pois, no tocante às limitadas, questões como a alienação de quotas e direito de preferência são mais frequentemente tratadas no âmbito do próprio contrato social, situação em que se apresentam mais protegidas contra eventuais questionamentos.

Nesse tocante, não é demais lembrar a lição do parágrafo único do artigo 997 do Código Civil, que prescreve ser "ineficaz em relação a terceiros qualquer pacto separado, contrário ao disposto no instrumento do contrato".

Dessa forma, por meio dos acordos de quotistas, os sócios das limitadas vinculam seus votos em reuniões ou assembleias (a depender do número de sócios, conforme o comando do Código Civil contido no artigo 1.072 e em seu $\left.1^{\circ}{ }^{\circ}\right)$, sendo necessário, no entanto, observar os limites da aplicação desses acordos às limitadas, a seguir examinados.

Em primeiro lugar, é preciso que os sócios de uma sociedade limitada que pretendam vincular seus votos, por meio de acordo de quotistas, 
observem se há previsão expressa no contrato social da aplicação supletiva da LSA, com vistas a eliminar as lacunas do referido documento, para que, desse modo, seja coerente - e possível - a aplicação do art. 118 da LSA, que prevê o acordo de acionistas.

Convém, aqui, lembrar a lição de Borba no tocante aos limites da aplicação supletiva da LSA:

atente-se, porém, para as limitações dessa regência supletiva. Aplicação supletiva não se confunde com aplicação subsidiária. Sendo supletiva, destina-se a suprir as omissões do contrato, incidindo naquelas hipóteses a respeito das quais poderia dispor o contrato [...] limitando-se, portanto ao que for compatível com a natureza e a condição da sociedade limitada (BORBA, 2003, p. 102).

O anteriormente exposto nos conduz à segunda limitação imposta ao acordo de quotistas, repise-se, com o perdão da redundância, no âmbito das sociedades limitadas, qual seja, a de que suas determinações jamais poderão contrariar o Código Civil, em sua parte do Direito de Empresa, tampouco o seu contrato social.

A doutrina apresenta, em sede de limitação de matérias, duas classificações de acordos de voto: os acordos de verdade e os acordos de vontade.

Os acordos de verdade - ou de substância - se revelam mais frágeis no tocante à sua configuração, pois tratam-se daqueles que pretendem sobrepor a substância do que será eventualmente deliberado aos interesses reais dos acordantes, a exemplo do que ocorrem com acordos celebrados para regular operações futuras sem que estejam presentes os elementos fundantes da decisão. Esse tipo de acordo pode ter sua nulidade decretada em juízo (CREUZ, 2007).

Com relação aos acordos de vontade, estes são amplamente aceitos, considerando o princípio da autonomia da vontade das partes e as limitações usualmente aplicáveis a tal princípio (CREUZ, 2007).

A despeito do artigo 118 da LSA indicar as matérias que podem ser tratadas por meio de acordo de acionistas, filiamo-nos à posição de 
Rachel Sztajn, no sentido de ampliação do rol de assuntos passíveis de serem tratados por acordo de acionistas ou de sócios:

a variedade das matérias objeto de acordos de sócios é, efetivamente, larga, podendo abranger desde voto - de forma ampla ou limitada - distribuição de resultados, preferência para a aquisição de quota de qualquer sócio que desejar retirar-se, indicação de, ou veto a, administradores, ou o que mais possa compor interesses de grupos membros da sociedade (SZTAJN, 2002, p. 275-276).

Contudo, não obstante o entendimento ora reproduzido, ou seja, da possibilidade de os acordos de acionistas serem celebrados com outros propósitos que não tão somente aqueles elencados no artigo 118 da LSA, é preciso esclarecer que "somente os que consagrarem os objetivos previstos na lei das sociedades anônimas gozarão da proteção por ela instituída" (BORBA, 2003, p. 357). Além disso, convém lembrar que, nos termos da LSA, o acordo de acionistas ou de quotistas apenas gerará para a sociedade, em relação aos participantes do acordo, o dever de uma prestação de caráter negativo, ou seja, o dever de evitar, naquilo que couber, atuação em sentido contrário ao acordo, quando tal instrumento for devidamente arquivado na sede da sociedade (artigo 118 e $\S 8^{\circ}-$ LSA).

O acordo de quotistas, a exemplo do de acionistas, tem natureza contratual e não societária, apesar de determinar direitos e obrigações de um grupo de sócios. E não se trata, como bem lembram Comparato e Salomão Filho, de contrato sui generis, mas sim de um contrato que se submete às normas gerais de validade de qualquer negócio jurídico privado (COMPARATO; SALOMÃO FILHO, 2008, p. 224).

Essa natureza, por sua vez, nos remete à terceira regra a ser observada em sede de acordo de quotistas, qual seja, a observância da norma contida no art. 104 do Código Civil, que dispõe sobre os requisitos de validade dos contratos, dentre outros negócios jurídicos, quais sejam: a necessidade de agente capaz; objeto lícito, possível, determinado ou determinável; e observância de forma prescrita em lei ou não proibida por esta. 
Assim, e apenas a título exemplificativo, o acordo de acionistas não poderia versar sobre a transferência e a venda de direitos de voto, qualificadas como crime pelo artigo $177, \S 2^{\circ}$ do Código Penal, pois isso configuraria a ilicitude do objeto e, consequentemente, estaria em descumprimento dos requisitos de validade do contrato.

Também em função de sua natureza contratual, pode-se inferir que o acordo de quotistas - a exemplo do de acionistas - poderá ser celebrado por prazo determinado ou indeterminado. Sendo o prazo determinado, os quotistas somente poderão se desvincular do acordo por mútuo consentimento ou pelo advento do término do prazo. Sendo por prazo indeterminado, qualquer das partes, em qualquer momento, poderá denunciar o acordo, nos termos previstos no próprio instrumento (BORBA, 2003, p. 358), que deverá, por tais razões, necessariamente, tratar do assunto, inclusive sobre eventuais penalidades.

Atente-se - aqui - para o fato de que o prazo indeterminado cria o inconveniente de fazer com que os acionistas ou quotistas, conforme o caso, convivam permanentemente com a possibilidade ou risco de denúncia de outros acionistas ou quotistas, o que fragiliza a necessária robustez do acordo.

\section{Conclusões}

Como se pretendeu demonstrar, vê-se que é perfeitamente possível que as sociedades limitadas empresárias se valham, mutatis mutandi, do acordo de acionistas previsto na LSA, que em seu âmbito se chamará acordo de quotistas, buscando - ao formatar tal instrumento - ter todo o suporte necessário para sua elaboração e tentativa de previsão do maior número possível de situações a serem abrangidas pelo acordo, bem como as regras que nortearão o comportamento dos sócios, estabelecendo, inclusive, punições àquele que as descumprir; e incentivos para o comportamento adequado dos acordantes.

Para isso, os sócios de sociedades limitadas empresárias deverão observar as seguintes questões: 
a) a previsão expressa no contrato social de regência supletiva da LSA de modo a viabilizar a aplicação do art. 118 da LSA pelos sócios;

b) os requisitos de validade de qualquer negócio jurídico privado, conforme o comando do artigo 104 do Código Civil;

c) os requisitos formais estabelecidos na LSA: arquivamento na sede e, logicamente, a forma escrita;

d) as limitações materiais aplicáveis: não contrariar as disposições do contrato social nem do Código Civil;

e) a despeito da variedade das matérias passíveis de serem objeto de acordos de sócios, atentar para o fato de que os acordos de sócios somente gozarão da proteção prevista na lei quando tratarem das matérias elencadas no artigo 118 da LSA, quais sejam, compra e venda de ações, preferência na aquisição, exercício do direito a voto ou poder de controle. Apenas nessas situações a sociedade pelos seus órgãos - estará obrigada à prestação negativa de impedir atuação em sentido contrário ao contrato parassocial;

f) priorizar a celebração de acordos com prazo determinado com vistas a evitar a convivência permanente com o risco da denúncia por qualquer das partes.

Observadas essas questões, acredita-se que o contrato parassocial, nascido no Direito Societário Brasileiro com a edição da LSA para servir aos acionistas das sociedades por ações, poderá ser de extrema valia aos sócios das limitadas empresárias.

\section{Referências}

BORBA, J. E. T. Direito societário. 8. ed. Rio de Janeiro: Renovar, 2003.

COMPARATO, F. K. Novos ensaios e pareceres. Rio de Janeiro: Forense, 1981. COMPARATO, F. K.; SALOMÃO FILHO, C. o poder de controle na sociedade anônima. 5. ed. Rio de Janeiro: Forense, 2008. 
CREUZ, L. R. C. E. Algumas linhas sobre os acordos de quotistas. 2007. Disponível em: 〈http://jusvi.com/artigos/28413〉. Acesso em: 20 jun. 2009. LAMY FILHO, A. Temas de S.A. Rio de Janeiro: Renovar, 2007. SZTAJN, R. Acordo de acionistas. In: SADDI, J. (Org.). Fusões e aquisições: aspectos jurídicos e econômicos. São Paulo: IOB, 2002. p. 273-294.

Recebido: 29/07/2009

Received: 07/29/2009

Aprovado: 22/09/2009 Approved: 09/22/2009 